\title{
Investigação de Desvio de Recursos Públicos na Polícia Federal: análise preliminar e CLASSIFICAÇÃo DAS NOTÍCIAS DE CRIME
}

Alex Silva Chagas

Polícia Federal - Brasil

$\approx$

RESUMO

O presente artigo científico tem a pretensão de analisar a forma como normalmente são recebidas, tratadas e distribuídas, na Polícia Federal, as notícias de crime de desvio de recursos públicos federais repassados às prefeituras municipais. Como, nesses casos, a instauração de numerosos inquéritos policiais, de imediato, a partir de notícias de crime isoladamente consideradas, sem nenhum tratamento prévio, contribui para a baixa efetividade das investigações, a partir do momento em que se perde o foco na possível atuação de uma organização criminosa, sem falar no uso inadequado dos poucos recursos humanos e materiais disponíveis. Propõe-se que, a despeito da obrigatoriedade da instauração do inquérito policial, as notícias de crimes que versem sobre o desvio de recursos públicos federais destinados às prefeituras sejam preliminarmente analisadas, com o objetivo de identificar a possível atuação de uma organização criminosa em comum, e posteriormente reunidas em um só procedimento investigatório, facilitando a desarticulação de todo o grupo criminoso e a punição de todos os envolvidos.

Palavras-Chave: Inquérito Policial. Obrigatoriedade. Notícia de Crime. Desvio de Recursos Públicos. Crime Organizado. Análise Preliminar.

\section{INTRODUÇÃ̃o}

A repressão ao desvio de recursos públicos federais repassados às prefeituras municipais, inserida em um contexto de enfrentamento da criminalidade organizada, tarefa eleita como prioritária pela Polícia Federal, demanda a utilização de ferramentas mais eficazes de investigação, como a colaboração premiada, a infiltração de agentes e a interceptação de comunicações telefônicas, dentre outras.

Mas não é só isso. É necessário, por oportuno, repensar antiquados métodos de investigação criminal, a começar pelo próprio tratamento das no- 
tícias-crime, aplicando-se conhecimentos de análise criminal e inteligência policial, com foco na identificação de organizações criminosas especializadas no desvio de recursos federais destinados aos municípios, bem como objetivando a redução do passivo de inquéritos policiais em andamento, instaurados para apurar fatos que, considerados isoladamente, muitas vezes possuem baixa lesividade. Igualmente, é preciso racionalizar o uso dos recursos disponíveis, elegendo as investigações que devem ser tomadas como prioritárias.

Nesse diapasão, o presente artigo tem como objetivo expor, em breves linhas, como ocorre, na prática, a investigação de desvio de recursos públicos federais repassados às prefeituras municipais e demonstrar a necessidade de tratamento prévio das notícias-crime de fatos dessa natureza, com o objetivo de dar maior efetividade às investigaçóes criminais e de reduzir o número de inquéritos policiais em andamento, sem comprometer sua dupla função de apurar infrações penais e evitar acusações infundadas.

Inicialmente, falaremos da investigação criminal formalizada mediante inquérito policial, das suas características e formas de início, abordando a questão da aplicação do princípio da obrigatoriedade já na fase pré-processual.

Passaremos, então, a analisar como a Polícia Federal normatizou o recebimento, tratamento e distribuição das notícias-crime e a instauração dos respectivos inquéritos policiais.

Em seguida, abordaremos, de forma resumida, a dinâmica das investigações de desvio de recursos públicos federais repassados às prefeituras municipais, como ocorre na prática, as características das organizações criminosas especializadas na prática de infrações penais dessa natureza e como a instauração indiscriminada de inquéritos policiais a partir de notícias-crime isoladamente consideradas e sem nenhuma análise prévia pode prejudicar a efetividade das investigações e a repressão à criminalidade organizada, além de contribuir para o aumento do número de procedimentos em andamento, comprometendo uma distribuição mais eficiente dos recursos humanos e materiais disponíveis.

Ao término, apresentaremos os resultados de uma operação desencadeada pela Polícia Federal em 2010, no Estado do Piauí, ainda antes da vigência da lei de combate ao crime organizado (Lei no 12.850/2013). A denominada "Operação Geleira" visou reprimir o desvio de recursos públicos 
federais repassados a várias prefeituras de municípios piauienses, ocasião em que foi identificada a atuação de uma rede criminosa integrada por falsos empresários e empresas de fachada, escritórios de contabilidade, agentes políticos e servidores públicos.

Pretendemos demonstrar que a análise prévia das notícias-crime de desvio de recursos públicos federais repassados às prefeituras municipais, classificando e reunindo em um só procedimento investigativo aquelas que possuem indícios da atuação de uma organização criminosa em comum, pode garantir uma maior efetividade das investigações e reduzir o passivo de inquéritos policiais em andamento ou por instaurar, racionalizando o uso dos recursos disponíveis.

\section{O Modelo de Investigação Criminal Brasileiro}

Como ensina Eliomar da Silva Pereira (PEREIRA, 2010, p. 87), a investigação criminal:

$$
\begin{aligned}
& \text { é uma pesquisa ou conjunto de pesquisas, administrada estrategica- } \\
& \text { mente, que, tendo por base critérios de verdade e métodos limitados } \\
& \text { juridicamente por direitos e garantias fundamentais, está dirigida a } \\
& \text { obter provas acerca da existência de um crime, bem como indícios de } \\
& \text { sua autoria, tendo por fim justificar um processo penal, ou a sua não } \\
& \text { instauração, se for o caso, tudo instrumentalizado sob uma forma } \\
& \text { jurídica estabelecida por lei (grifo do autor). }
\end{aligned}
$$

É ela, portanto, um processo concatenado de atos tendentes a descobrir a prova da materialidade delitiva e colher indícios suficientes de autoria, mediante utilização de técnicas e métodos próprios. Esse processo ocorre desde o recebimento da notícia-crime até a apresentação do respectivo relatório contendo as conclusões colhidas durante a investigação.

São vários os sistemas de investigação criminal, mas podemos dizer que eles podem ser classificados basicamente em três tipologias, conforme a autoridade responsável pela sua direção: policial, ministerial ou judicial. No Brasil, conforme se depreende da leitura do Código de Processo Penal (CPP, Art. $5^{\circ}$ e ss.) e de sua exposição de motivos (abaixo transcrita), o legislador optou pelo sistema de investigação criminal policial, conduzida pelas polícias judiciárias sob a direção dos delegados de polícia e formalizada por meio do inquérito policial: 
Investigação de desvio de recursos públicos na Polícia Federal

Foi mantido o inquérito policial como processo preliminar ou preparatório da ação penal, guardadas as suas caracteristicas atuais. O ponderado exame da realidade brasileira, que não é apenas a dos centros urbanos, senão também a dos remotos distritos das comarcas do interior, desaconselha o repúdio do sistema vigente. O preconizado juizo de instrução, que importaria limitar a função da autoridade policial a prender criminosos, averiguar a materialidade dos crimes e indicar testemunhas, só épraticável sob a condição de que as distâncias dentro do seu território de jurisdição sejam fácil e rapidamente superáveis. Para atuar proficuamente em comarcas extensas, e posto que deva ser excluida a hipótese de criação de juizados de instrução em cada sede do distrito, seria preciso que o juiz instrutor possuisse o dom da ubiquidade. De outro modo, não se compreende como poderia presidir a todos os processos nos pontos diversos da sua zona de jurisdição, a grande distância uns dos outros e da sede da comarca, demandando, muitas vezes, com os morosos meios de condução ainda praticados na maior parte do nosso hinterland, vários dias de viagem, seria imprescindivel, na prática, a quebra do sistema: nas capitais e nas sedes de comarca em geral, a imediata intervenção do juiz instrutor, ou a instrução única; nos distritos longinquos, a continuação do sistema atual. Não cabe, aqui, discutir as proclamadas vantagens do juizo de instrução. Preliminarmente, a sua adoção entre nós, na atualidade, seria incompativel com o critério de unidade da lei processual. Mesmo, porém, abstraida essa consideração, há em favor do inquérito policial, como instrução provisória antecedendo a propositura da ação penal, um argumento dificilmente contestável: é ele uma garantia contra apressados e errôneos juizos, formados quando ainda persiste a trepidação moral causada pelo crime ou antes que seja possivel uma exata visão de conjunto dos fatos, nas suas circunstâncias objetivas e subjetivas. Por mais perspicaz e circunspeta, a autoridade que dirige a investigação inicial, quando ainda perdura o alarma provocado pelo crime, está sujeita a equívocos ou falsos juizos a priori, ou a sugestões tendenciosas. Não raro, é preciso voltar atrás, refazer tudo, para que a investigação se oriente no rumo certo, até então despercebido. Por que, então, abolir se o inquérito preliminar ou instrução provisória, expondo se a justiça criminal aos azares do detetivismo, às marchas e contramarchas de uma instrução imediata e única? Pode ser mais expedito o sistema de unidade de instrução, mas o nosso sistema tradicional, com o inquérito preparatório, assegura uma justiça menos aleatória, mais prudente e serena. 
Nos termos da Constituição Federal de 1988 (CF/88) e da Lei no 12.830/2013 (que dispõe sobre a investigação criminal conduzida pelo delegado de polícia), a presidência do inquérito policial cabe ao delegado de polícia de carreira, autoridade de polícia judiciária, bacharel em direito, que possui discricionariedade na condução das investigações criminais e das diligências necessárias à elucidação das infrações penais.

Frisamos que, a despeito do Ministério Público (MP), titular da ação penal pública, poder colher por outros meios os elementos de convicção necessários para dar início à persecução criminal in judicio, certo é que o inquérito policial é o único procedimento formalmente disciplinado em lei (em sentido estrito), com a finalidade exclusiva de apuração de infrações penais.

Portanto, no Brasil, a investigação criminal realizada pelas polícias judiciárias (Polícia Federal e polícia civis estaduais, nos termos da CF/88, Art. $144, \S 1^{\circ}$, I, II e IV, e $₫ 4^{\circ}$ ) materializa-se por meio do inquérito policial, que é presidido e dirigido por delegado de polícia.

No que diz respeito à Polícia Federal, o poder constituinte a incumbiu de uma série de atribuições, dentre as quais: apurar infrações penais contra a ordem política e social ou em detrimento de bens, serviços e interesses da União ou de suas entidades autárquicas e empresas públicas, assim como outras infrações cuja prática tenha repercussão interestadual ou internacional e exija repressão uniforme, prevenir e reprimir o tráfico de entorpecentes, $\mathrm{o}$ contrabando e o descaminho, bem como exercer, com exclusividade, as funções de polícia judiciária da União.

Assim, constitui como uma das tarefas da Polícia Federal a investigação de desvio de recursos públicos federais repassados pela União às prefeituras municipais, através de transferências decorrentes da própria $\mathrm{CF} / 88$ ou de leis específicas, bem como das transferências voluntárias (convênios, contratos de repasse etc.), prática ilícita que normalmente vem acompanhada de outras condutas delituosas de considerável gravidade e potencial lesivo, tais como lavagem dinheiro, participação em organização criminosa, crimes previstos na lei de licitações (Lei no 8.666/1993), dentre outras, o que demonstra a complexidade e a importância da repressão dessas infrações penais.

\section{I CONCEITO DE INQUÉRITO POLICIAL}


Embora a legislação processual penal vigente não estabeleça um conceito de inquérito policial ${ }^{1}$, o Art. 42 da Lei n ${ }^{\circ} 2.033 / 1871$, já revogada, o definiu da seguinte forma: "o inquérito policial consiste em todas as diligências necessárias para o descobrimento dos fatos criminosos, de suas circunstâncias e de seus autores e cúmplices, devendo ser reduzido a instrumento escrito" (MARCÃO, 2014, cap. 5).

Guilherme de Souza Nucci, com muita precisão, conceitua o inquérito policial como "um procedimento preparatório da ação penal, de caráter administrativo, conduzido pela polícia judiciária e voltado à colheita preliminar de prova para apurar a prática de uma infração penal e sua autoria" (NUCCI, 2016, cap. 9).

Renato Marcão afirma que o inquérito policial é "o principal instrumento de que se vale o Estado para a investigação de fato tipificado como delito", sendo ele um "procedimento administrativo de natureza investigatória, instaurado e presidido pela polícia judiciária com a finalidade de apurar a ocorrência de determinado fato apontado como ilícito penal, sua autoria e eventual materialidade, com todas as suas circunstâncias" (MARCÃO, op. cit., passim).

É o inquérito policial, portanto, um procedimento pré-processual, de natureza administrativa, dirigido pelo delegado de polícia, que tem por objetivo apurar a materialidade e autoria de infrações penais comunicadas à polícia judiciária, justificando ou não a propositura de eventual ação penal.

Possui, dessa forma, dupla função: se, por um lado, o inquérito policial se presta a subsidiar o titular da ação penal para o ingresso em juízo, fornecendo elementos de convicção quanto à autoria e materialidade delitivas, inclusive realizando cautelarmente a coleta de provas perecíveis e irrepetíveis em juízo; por outro lado, objetiva também evitar acusações infundadas e precipitadas, assim como a instauração de um processo penal sem justa causa, em clara observância dos princípios norteadores de um direito processual penal garantista, resguardando a liberdade do inocente e evitando custos desnecessários ao Estado (BRASILEIRO, 2016).

1 O código de processo penal português, diferentemente do brasileiro, por exemplo, contém uma definição de inquérito, estabelecendo que ele compreende o conjunto de diligências que visam investigar a existência de um crime, determinar os seus agentes e a responsabilidade deles e descobrir e recolher as provas, em ordem à decisão sobre a acusação (CPP português, Art. 262, n 1 ). Ressalte-se, entretanto, que, no processo penal luso, o inquérito (que não é policial), constitui uma das fases do processo, cuja direção cabe ao MP. 


\section{I.2 CARACTERÍSTICAS DO INQUÉRITO POLICIAL}

O inquérito policial é um procedimento administrativo, não podendo ser considerado processo, uma vez que o órgão encarregado de sua condução, no caso, a polícia judiciária, não dispõe de poder jurisdicional.

É sigiloso, por força do Art. 20 do CPP, que dispõe que o delegado de polícia e seus agentes assegurarão o sigilo necessário à elucidação do fato ou exigido pelo interesse da sociedade e para proteção da intimidade do investigado. O sigilo do inquérito policial, nos termos da $\mathrm{CF} / 88$ e da legislação vigente, bem como da Súmula no 14 do Supremo Tribunal Federal (STF), não pode ser oposto à defesa, sendo prerrogativa desta o acesso amplo aos autos e ao conteúdo das diligências já produzidas.

É escrito, pois todas as diligências e atos realizados devem ser necessariamente formalizados e documentados, de forma a demonstrar a legalidade de sua produção e possibilitar ao investigado o exercício da ampla defesa e do contraditório desde a investigação criminal preliminar até a sentença final.

O inquérito policial é inquisitivo, isto é, não está submetido ao contraditório, muito embora haja previsão de que o investigado possa indicar ao delegado de polícia a realização de diligências que julgue necessárias ao exercício da ampla defesa. Contudo, o delegado de polícia não está obrigado a realizá-las, podendo recusar o requerimento de diligências, sempre de forma fundamentada.

Quanto à dispensabilidade do inquérito policial, a melhor leitura que podermos fazer de tal característica é que, para o oferecimento da denúncia, o Ministério Público pode prescindir do inquérito policial, se possuir elementos de convicção suficientes para tanto. Entretanto, nos crimes de ação penal pública incondicionada, ao tomar conhecimento de uma infração penal, o delegado de polícia está obrigado a iniciar a persecução criminal. Portanto, o inquérito policial é dispensável somente no caso de o titular da ação penal ter colhido as provas da materialidade delitiva e indícios suficientes de autoria por outros meios (SILVA, 2016, p. 25). 
Investigação de desvio de recursos públicos na Polícia Federal

\section{3 DA NOTITIA CRIMINIS}

Conforme exposto, em regra, o delegado de polícia, por força do princípio da obrigatoriedade, ao tomar conhecimento de um determinado fato enquadrado como crime, deverá instaurar o respectivo inquérito policial. A esse conhecimento, seja ele espontâneo ou provocado, se dá o nome de notitia criminis ou notícia-crime.

"É com a notícia da prática de um delito que se põe em movimento a máquina estatal de persecução criminal” (BARBOSA, 2010, p. 157).

A doutrina costuma classificar a notícia-crime da seguinte forma: de cognição imediata ou espontânea, de cognição mediata ou provocada, de cognição coercitiva e inqualificada (SILVA, 2016, pp. 26-28).

A notitia criminis de cognição imediata ou espontânea é a que se dá por meio das atividades de rotina da própria polícia judiciária ou obtidas através da mídia, por exemplo. Nessas situações, havendo fundamentos de fato e de direito que indiquem a prática de uma infração penal, deve o delegado de polícia instaurar o respectivo inquérito policial.

Como notícia-crime de cognição mediata ou provocada entende-se aquela que se dá por meio de expediente escrito, como no caso das requisições judiciais e do MP, assim como no das representações do ofendido ou de qualquer do povo que venha a tomar conhecimento da prática de algum fato delituoso (delatio criminis).

Importante ressaltar que as requisições do MP não são um gênero em si, mas uma espécie de notícia-crime, que não se reveste do caráter de ordem, por não haver uma relação de subordinação entre as polícias judiciárias e aquele órgão. O delegado de polícia se encontra obrigado a instaurar inquérito policial no caso das requisições, assim como ocorre com qualquer outra notícia-crime, por força do princípio da obrigatoriedade, no caso de se tratar de ação penal pública. Dessa forma, caso a requisição ministerial não se encontre devidamente fundamentada ou demonstre ser manifestamente ilegal (ausência de atribuição do órgão requisitado, atipicidade do fato, presença de alguma causa extintiva da punibilidade etc.), pode o delegado de polícia deixar de instaurar o respectivo inquérito policial, sempre mediante decisão fundamentada. 
Da leitura dos dispositivos legais que regulamentam o inquérito policial no CPP, destacando-se o Art. 16, verificamos, também, que não cabe ao MP, já na requisição de instauração de inquérito policial, determinar quais as diligências que deseja ver ou não realizadas, pois o delegado de polícia goza de total autonomia tática e técnica na condução das investigações, cabendo a ele decidir qual a melhor forma de colher os elementos necessários à elucidação dos fatos supostamente criminosos e o momento oportuno para desencadear a ação estatal, de forma a não prejudicar o resultado útil das investigações criminais por ele dirigidas. O MP tem a oportunidade de requisitar novas diligências somente após apresentação do relatório conclusivo.

A notícia-crime é de cognição coercitiva nos casos de prisão em flagrante, em que o preso é apresentado ao delegado de polícia, que, convencendo-se da presença de indícios razoáveis da prática de infração penal tipificada, deve determinar a elaboração do respectivo auto de prisão em flagrante (CPP, Arts. $8^{\circ}, 301$ e ss.).

Por fim, classifica-se como inqualificada a notícia-crime anônima ou apócrifa, ou seja, aquela que não possui a identificação do respectivo autor. Por força da jurisprudência do STF (HC 98.345/RJ, Rel. Min. Marco Aurélio, Rel. para o acórdão Min. Dias Toffoli, DJ de 17/09/2010) a notícia-crime anônima somente pode fundamentar a instauração de inquérito policial se precedida por diligências preliminares que visem confirmar a verossimilhança dos fatos nela contidos (SILVA, 2016, pp. 26-28).

\section{I.4 FORMAS DE INSTAURAÇÃO DO INQUÉRITO POLICIAL}

Segundo o CPP, nos crimes de ação penal pública, o inquérito policial pode iniciar-se de ofício (CPP, Art. $5^{\circ}$, inciso I), mediante requisição da autoridade judiciária ou do MP, ou a requerimento do ofendido ou de seu representante legal (CPP, Art. $5^{\circ}$, inciso II), após notícia-crime oferecida por qualquer do povo (CPP, Art. $\left.5^{\circ}, \S 3^{\circ}\right)$ e, ainda, por auto de prisão em flagrante (CPP, Arts. 300 e ss.).

Em relação á Polícia Federal, caber acrescentar que há a possibilidade de instauração de inquérito policial mediante autorização ou determinação do Ministro da Justiça, nos casos de infrações penais que tenham repercussão interestadual ou internacional que exijam repressão uniforme, que não constem do rol taxativo da legislação de regência (Art. $1^{\circ}$, parágrafo único, da Lei no ${ }^{\circ}$ 10.446/2002). 
Já em relação aos crimes de ação penal pública condicionada, esta só terá início com a representação da vítima $\left(\mathrm{CPP}\right.$, Art. $\left.5^{\circ}, \S 4^{\circ}\right)$. O mesmo ocorre em relação aos crimes de ação penal de iniciativa privada, onde o delegado de polícia somente poderá proceder ao inquérito policial após queixa apresentada pelo ofendido (CPP, Art. $5^{\circ}, \S 5^{\circ}$ ).

\section{I.5 DA OBRIGATORIEDADE DO INQUÉRITO POLICIAL}

Dissemos anteriormente que, por força do princípio da obrigatoriedade ou da legalidade processual, logo que tomar conhecimento de notíciacrime, o delegado de polícia, deve instaurar imediatamente o inquérito policial (observando-se a necessidade de representação do ofendido, nos casos de ação penal pública condicionada, e de queixa, nos caso de ação penal privada).

O princípio da obrigatoriedade da ação penal ou da legalidade processual, como é referido no direito português, encontra-se consagrado no CPP em seus Arts. $5^{\circ}, 6^{\circ}$ e 24, sendo aplicável tão somente aos crimes de ação penal pública incondicionada, em oposição ao princípio da oportunidade, aplicável às ações penais privadas e às públicas condicionadas à representação do ofendido ou à requisição o Ministro da Justiça.

Luigi Ferrajoli (FERRAJOLI, 2002, p. 457) define o postulado da obrigatoriedade como "a obrigação dos órgãos de acusação pública de promover o juízo para toda notitia criminis que vier a seu conhecimento - ainda que para requerer o arquivamento ou a absolvição caso considerem o fato penalmente irrelevante ou faltarem indícios de culpabilidade".

Nas palavras de Figueiredo Dias, "a consagração do princípio da legalidade é, em princípio e face ao que fica dito, de aplaudir; ela preserva um dos fundamentos essenciais do Estado-de-direito, enquanto põe a justiça penal a coberto de suspeitas e tentações de parcialidade e arbítrio" (FIGUEIREDO DIAS, 1981, p. 128).

Diante de uma notícia-crime de um "fato criminal processável por ação penal pública incondicionada", ou havendo representação ou queixa do ofendido (nos casos de ação penal pública condicionada e de ação penal privada, respectivamente), "a autoridade policial deverá desencadear o procedimento investigatório (dever de atuar), desenvolvê-lo e concluí-lo (não arquivar), não podendo dispor (selecionar) dos fatos e nem dos agentes segundo 
critérios subjetivos de conveniência" (GIACOMOLLI, 2011, pp. 75-76). Por força do princípio da obrigatoriedade, portanto, o delegado de polícia está obrigado a instaurar o respectivo inquérito policial, em virtude da indisponibilidade do interesse público.

Contudo, entendemos que cabe ao delegado de polícia um juízo discricionário de conveniência e oportunidade, de modo que possa verificar a melhor forma e o momento mais adequado para dar início ao inquérito policial, desde que de acordo com critérios objetivos previamente estabelecidos e em um prazo razoável, priorizando as notícias-crime mais relevantes e de grande potencial lesivo, com a finalidade de dar uma maior efetividade às investigações e melhor gerir os recursos humanos e materiais disponíveis.

Não pretendemos a adoção pura e simples do princípio da oportunidade na fase pré-processual, onde o delegado de polícia estaria livre, segundo suas próprias convicções, para decidir sobre a instauração do inquérito policial, dando margem a possíveis direcionamentos indevidos das investigações, a interferências externas danosas ou a uma seletividade investigativa indesejável em um Estado Democrático de Direito, fundado no respeito da dignidade da pessoa humana e da igualdade. Afinal, "os encarregados da investigação, ante a notitia criminis, possuem o dever de atuar” (GIACOMOLLI, 2014, p. 277).

Ainda que se admita a opção pela possibilidade de aplicação do princípio da oportunidade pela polícia judiciária, essa opção "deve reger-se segundo critérios de objectividade e de isenção", de modo a não aniquilar a legalidade e boa-fé da atuação policial (VALENTE, 2016, p. 217).

Propomos, na realidade, uma mitigação da obrigatoriedade, ou melhor, uma discricionariedade regrada (LOPES JR. 2013, p. 382), permitindose ao delegado de polícia adotar estratégias, rotinas de análise e classificação das notícias-crime, priorizando investigações mais relevantes para sociedade, de acordo com critérios objetivos, como a gravidade da lesão e a relevância do bem jurídico tutelado. Afinal, "a discricionariedade da autoridade policial insere-se nas linhas investigatórias de atuação (como, quem, onde e o que investigar), na realização de diligências e na produção de elementos probatórios", cabendo ao delegado de polícia "dirigir formal e materialmente toda a fase preliminar, mantendo-a sob seu comando e controle, ditando as diretrizes, ordens, modus procedendi" (GIACOMOLLI, 2011, pp. 76-77). 
Aliás, no ordenamento jurídico brasileiro já há previsão de hipóteses de mitigação da obrigatoriedade, como no caso da Lei n. 9.099/1995, que criou os Juizados Especiais Cíveis e Criminais com competência para o processamento, julgamento e execução das infrações penais de menor potencial ofensivo, onde se encontra prevista a possibilidade de composição civil do dano ocasionado pelo delito como causa de exclusão do processo (Art. $74 \mathrm{da}$ Lei no 9.099/1995) e, ainda, se estabelece hipóteses de aplicação imediata da pena não privativa de liberdade, mediante transação penal ofertada pelo MP (Art. 76 da Lei no 9.099/1995).

É possível também verificar essa mitigação do princípio da obrigatoriedade na própria Lei $\mathrm{n}^{\circ} 12.850 / 2013$, quanto trata do instituto da colaboração premiada, quando prevê, inclusive, a possibilidade de perdão judicial ao colaborador (Art. $4^{\circ}$, caput, da Lei no $12.850 / 2013$ ).

\section{Do Início do Inquérito Policial na Polícia Federal}

Até o dia 7 de novembro de 2016, a atividade de polícia judiciária na Polícia Federal se encontrava regulamentada pela Instrução Normativa ${ }^{\circ}$ 11-DG/DPF, de 27 de junho de 2001. Havia a previsão de as notícia-crime recebidas pelas unidades da Polícia Federal deveriam ser encaminhadas à Corregedoria-Geral, às respectivas corregedorias regionais ou ao chefe de delegacia descentralizada, conforme o caso, para fins de registro e manifestação quanto à atribuição investigativa do órgão, sendo posteriormente encaminhadas às autoridades responsáveis pela distribuição e destas ao delegado de Polícia Federal designado para presidir o respectivo inquérito policial, para instauração imediata.

Dessa forma, as corregedorias ou chefes de delegacia descentralizada se limitavam a analisar se a Polícia Federal possuía atribuição para investigar os fatos noticiados e verificar se já havia inquérito policial em andamento, com o mesmo objeto, de forma a evitar o bis in idem.

Caso o distribuidor ou o delegado de Polícia Federal eventualmente designado para presidir o inquérito policial não concordasse com sua instauração, a notícia-crime deveria ser restituída às corregedorias ou aos chefes das delegacias descentralizadas, para nova manifestação. Havendo concordância 
das corregedorias ou dos chefes das delegacias descentralizadas, o noticiante deveria então ser comunicado da decisão, da qual caberia recurso à autoridade superior. Constatada a ausência de atribuição da Polícia Federal, a notíciacrime deveria ser encaminhada à autoridade competente.

No que diz respeito às requisições, embora passíveis de indeferimento, na hipótese do MP insistir com a necessidade de instauração do inquérito policial, o delegado de Polícia Federal deveria cumprir a requisição e instaurar o respectivo procedimento, caso a requisição não fosse manifestamente ilegal.

Conforme n ${ }^{\circ} 6$ da Instrução Normativa no 11-DG/DPF, de 27 de junho de 2001, quando os fatos noticiados não possibilitassem a instauração imediata de inquérito policial, sua procedência deveria ser averiguada, com vista à confirmação da existência da infração penal, na forma prevista no $\$ 3^{\circ}$, Art. $5^{\circ}$ do CPP. Aqui já se previa hipótese de não instauração imediata do inquérito policial, possibilitando uma melhor análise e enquadramento dos fatos noticiados.

Entretanto, a partir de 8 de novembro de 2016, passou a vigorar no âmbito da Polícia Federal a Instrução Normativa no 108 -DG/PF, em substituição à Instrução Normativa no 11-DG/DPF, de 27 de junho de 2001.

Em seu Art. $3^{\circ}$, a Instrução Normativa no $108-\mathrm{DG} / \mathrm{PF}$ estabelece os princípios que devem orientar a atividade de polícia judiciária na Polícia Federal, sendo eles: legalidade, moralidade, impessoalidade, eficiência, razoabilidade, celeridade, economicidade e instrumentalidade das formas.

Há também previsão expressa de que a "distribuição de meios e recursos disponíveis à investigação atenderá à gravidade e à complexidade dos fatos investigados, à potencialidade lesiva da conduta delituosa e à natureza jurídica do bem penalmente tutelado" (Art. $3^{\circ}, \$ 2^{\circ}$, da Instrução Normativa n ${ }^{\circ}$ 108-DG/PF).

Resta clara a intenção da Polícia Federal de priorizar as investigações mais complexas e que tenham um potencial lesivo considerável, bem como aquelas em que o bem jurídico penalmente tutelado seja mais relevante, como é o caso das investigações que visam o combate ao crime organizado, à corrupção, aos crimes financeiros, à lavagem de dinheiro e ao desvio de recursos públicos.

A regra em questão se aplica desde o recebimento e análise prévia das notícia-crime, identificando-se aquelas de maior potencial lesivo e cujo 
Investigação de desvio de recursos públicos na Polícia Federal

bem jurídico penalmente tutelado seja mais relevante, se possível reunindo em um só procedimento investigatório, evitando-se a instauração de vários procedimentos para investigar fatos que podem ser atribuídos a uma única organização criminosa, por exemplo.

Destaque-se, ainda, o disposto no Art. $9^{\circ}$ da Instrução Normativa ${ }^{\circ}$ 108-DG/PF, de 08 de novembro de 2016, onde se estabelece que, na análise das notícia-crime, deverá ser observada a existência de investigação conexa em andamento, projetos ou rotinas de trabalho formalmente instituídas, que visem ao tratamento de informações, à classificação e ao agrupamento das notícias, de acordo com as circunstâncias do cometimento da prática delituosa ou de sua autoria, a fim de otimizar os recursos empregados nas investigações. Mais uma vez, a nova instrução normativa, possibilitou a análise prévia das notícia-crime, com a finalidade de classificação e agrupamento, antes da instauração do respectivo inquérito policial.

Por fim, o Art. 18 da Instrução Normativa no 108-DG/PF, de 08 de novembro de 2016, prevê que, quando a notícia-crime for anônima ou não possibilitar a imediata instauração de inquérito policial, a Corregedoria-Geral, a Corregedoria-Regional ou Chefe de Delegacia descentralizada determinarão, conforme o caso, a verificação de procedência de informações, nos termos da lei, sendo vedadas, nessa fase, intimações, representações por medidas cautelares e apreensões, salvo de coisas encaminhadas com a própria notícia-crime, devendo as entrevistas e diligências realizadas constarem de informação policial produzida pelo agente de Polícia Federal responsável pelas investigações preliminares.

\section{Da Investigação de Desvio de Recursos Públicos}

A repressão ao desvio de recursos públicos, à corrupção e ao crime organizado é prioridade da Polícia Federal, instituição que vem desempenhando papel de destaque no combate a tais modalidades delituosas, devido ao know-how adquirido nos últimos anos em diversas operações policiais realizadas, destacando-se atualmente a denominada "Operação Lava Jato".

Segundo Felipe Eduardo Hideo Hayashi, a "corrupção é um complexo fenômeno global" que "afeta o desenvolvimento de todos os países do 
mundo", contribuindo, dessa forma, para a concentração de renda e aumento das desigualdades sociais (HAYASHI, 2015, p. 11).

Conforme Manual de Investigação de Desvio de Recursos Públicos da Polícia Federal (2011, p. 9), dados da Fundação Getúlio Vargas apontam que o Brasil perde 5\% do PIB (produto interno bruto) a cada ano por causa da corrupção, o que gera consequências graves, como a insuficiência e até mesmo ausência de prestação de serviços públicos básicos, privando grande parte da população de condições satisfatórias e mais humanas de existência.

Como vimos acima, a Polícia Federal, nos termos do Art. 144, $\$ 1^{\circ}$, inciso $\mathrm{I}$, da $\mathrm{CF} / 88$, tem como atribuição apurar as infrações penais praticadas em detrimento de bens, serviços e interesses da União ou de suas entidades autárquicas e empresas públicas.

Nesse contexto, frequentemente os delegados de Polícia Federal se deparam com notícia-crime de desvio de recursos públicos repassados pela União às prefeituras municipais, constituindo-se essa matéria, sem sombra de dúvidas, uma das maiores causas de instauração de inquéritos policiais federais.

A investigação de desvio de recursos públicos repassados às prefeituras municipais envolve algumas peculiaridades, decorrentes da cultura de gestão implantada na administração pública em geral e nos executivos municipais em especial, caracterizada pelo nepotismo, pelo apadrinhamento e pela confusão entre o público e o privado, onde o locupletamento de alguns poucos, detentores do poder político e econômico, se sobrepõe à satisfação dos interesses públicos mais básicos da população, como a saúde e a educação.

Um das formas mais comuns utilizadas para o cometimento de crimes dessa natureza é a utilização de empresas de fachada ou "fantasmas", isto é, pessoas jurídicas ou empresas individuais constituídas legalmente, mas que não existem de fato, não exercem quaisquer atividades e servem apenas para fornecer notas fiscais "frias" ou inidôneas, com o objetivo de justificar gastos públicos com a aquisição de mercadorias que não são verdadeiramente entregues e com a prestação de serviços que não são efetivamente prestados. Ou seja, ao invés de serem aplicados na finalidade prevista pelo ordenamento jurídico, os recursos são desviados em benefícios de agentes políticos (prefeito e vereadores), servidores públicos municipais e terceiros (empresários, advogados, contadores etc.). 
É comum também a fraude em processos licitatórios e o conluio entre os participantes, em regra, com a conivência de agentes políticos e servidores públicos, impedindo a livre concorrência entre os licitantes e ocasionando graves prejuízos ao erário, com a aquisição de mercadorias e contratação de serviços e obras superfaturados.

Percebe-se assim que são criadas verdadeiras estruturas criminosas em torno das prefeituras municipais, integradas por agentes políticos, servidores públicos, empresas de fachada, escritórios de contabilidade e de assessoria jurídica, cuja finalidade única e exclusiva é o desvio de recursos públicos repassados pela União.

Ocorre que, a partir da análise de um fato isolado ocorrido em um determinado município, nem sempre é possível perceber o funcionamento dessa engrenagem delituosa, pela forma difusa em que normalmente se encontra estruturada, muitas vezes sem uma hierarquia padrão.

Como regra, a grande maioria dos inquéritos policiais instaurados dessa forma, isto é, a partir de notícia-crime de infrações penais isoladamente consideradas e limitadas a um município, fora de um contexto de repressão à criminalidade organizada e sem uma análise preliminar, possuem uma baixa efetividade, alcançando, em geral, apenas uma pequena parte dos envolvidos e possibilitando a perpetuação das práticas ilícitas.

A investigação de desvio de recursos públicos federais repassados às prefeituras, seja pela complexidade dos fatos apurados, seja pela potencial atuação de organizações criminosas especializadas, demanda a utilização de técnicas mais eficazes de repressão, bem como a utilização dos conhecimentos de análise e inteligência policial, desde o recebimento e tratamento das notícia-crime, identificando e reunindo aquelas que podem ser inseridas em um mesmo contexto (determinada base territorial, coincidência de envolvidos, ligações político-partidárias entre os agentes políticos e sócios das empresas contratadas etc.).

\section{Crime Organizado e Investigação Criminal}

Muitas são as dificuldades encontradas na investigação criminal de desvio de recursos públicos, principalmente quando tais crimes são come- 
tidos por uma organização criminosa, tendo em vista ora a deficiência ou insuficiência da legislação, ora as próprias características da criminalidade organizada.

Hassemer define o crime organizado como "um fenómeno criminógeno, cujas estruturas operativas policiais e judiciárias e cujo ordenamento jurídico processual penal vigente num determinado tempo e espaço se manifestam incapazes de prevenir" (apud VALENTE, 2009, p. 159), dada a complexidade de identificação e comprovação do funcionamento dessas estruturas criminosas.

A Convenção das Nações Unidas contra o Crime Organizado Transnacional, ou simplesmente Convenção de Palermo, devidamente incorporada ao nosso ordenamento jurídico (Decreto $\mathrm{n}^{\circ} 5.015$, de 12 de março de 2004), transformou-se no principal instrumento global de combate ao crime organizado transnacional e prevê, dentre outras coisas, que os países signatários se comprometam a adotar uma série de medidas contra a criminalidade organizada transnacional, incluindo a tipificação da participação em organizações criminosas, lavagem de dinheiro, corrupção e obstrução da justiça.

Segundo a Convenção de Palermo, uma organização criminosa poder ser definida como um "grupo estruturado de três ou mais pessoas, existente há algum tempo e atuando concertadamente com o propósito de cometer uma ou mais infrações graves ou enunciadas na presente Convenção, com a intenção de obter, direta ou indiretamente, um benefício econômico ou outro benefício material".

Já o Federal Bureau of Investigation (FBI), define o crime organizado como qualquer grupo de alguma forma estruturado, cujo objetivo principal é o lucro a partir da prática de atividades ilegais (disponível em: https://www.fbi.gov/investigate/organized-crime). Tais grupos costumam se utilizar da violência e da corrupção de autoridades públicas para realizar suas atividades ilícitas.

O crime organizado caracteriza-se, pois, "por um determinado modus operandi, com divisão de tarefas, utilização de métodos sofisticados, existência, por vezes, de simbiose com o Poder Público, além de alto poder de intimidação" (DE SANCTIS, 2015, cap. 1). Seu desenvolvimento "apresenta-se dissimulado ou encoberto por atividade comercial lícita” (ibidem). 
Investigação de desvio de recursos públicos na Polícia Federal

A Lei n. 12.694/2012, que dispóe sobre o processo e o julgamento colegiado em primeiro grau de jurisdição de crimes praticados por organizações criminosas, conceituou organização criminosa em seu Art. $2^{\circ}$ da seguinte forma:

considera-se organização criminosa a associação, de 3 (três) ou mais pessoas, estruturalmente ordenada e caracterizada pela divisão de tarefas, ainda que informalmente, com objetivo de obter, direta ou indiretamente, vantagem de qualquer natureza, mediante a prática de crimes cuja pena máxima seja igual ou superior a 4 (quatro) anos ou que sejam de caráter transnacional.

No entanto, a tipificação do crime organizado ocorreu somente com a edição da Lei $\mathrm{n}^{\circ} 12.850 / 2013$, que adotou conceito um pouco diferente (Art. $1^{\circ}, \$ 1^{\circ}$, da Lei no $12.850 / 2013$ ):

Associação de 4 (quatro) ou mais pessoas estruturalmente ordenada e caracterizada pela divisão de tarefas, ainda que informalmente, com objetivo de obter, direta ou indiretamente, vantagem de qualquer natureza, mediante a prática de infraçôes penais cujas penas máximas sejam superiores a 4 (quatro) anos, ou que sejam de caráter transnacional.

Visto o conceito legal, é preciso tecer alguns comentários acerca das características ou fatores que identificam uma organização criminosa.

Guilherme Cunha Werner, citando Abadinsky, estabelece os seguintes critérios para o estudo do crime organizado transnacional, delimitando o seu exato significado: 1) não apresenta motivação política, buscando apenas o ganho ilícito e o poder; 2) estrutura hierarquizada; 3) a participação de seus membros é definida pelas qualidades individuais de cada um; 4) os integrantes formam uma subcultura, aceitando os comportamentos e as regras do grupo, distintas das adotadas pela sociedade; 5) perpetuação, com a integração de novos membros; 6) uso da força e da corrupção; 7) especialização e divisão de tarefas; 8) monopólio das atividades ilícitas, visando à hegemonia na distribuição de determinados bens ou serviços; 9) comando mediante normas e regras prévias, como se fosse uma organização legalmente constituída (ABADINSKY apud WERNER, 2009, pp. 42-43).

Vicente Greco Filho também aponta alguns traços distintivos do crime organizado indicados pela doutrina (GRECO FILHO, 2014, cap. 1): 
a) Estrutura organizacional, com células relativamente estanques, de modo que uma não tem a identificação dos componentes da outra;

b) Especialização de tarefas, de modo que cada uma exerce uma atividade predominante. Tomando como exemplo uma organização criminosa para o tráfico ilícito de entorpecentes, dir-se-ia que tem atividade definida o importador, o transportador, o destilador, o financeiro, o traficante de área e distribuidor e o traficante local, como uma rede, das artérias aos vasos capilares;

c) A existência de vários niveis de hierarquia, em que os subordinados nem sempre, ou quase nunca, conbecem a identidade da chefia de dois ou mais escalões superiores ou ainda que conheçam a chefia mais elevada não têm contato direto com ela e não podem fornecer provas a respeito;

d) A possivel existência de infiltração de membros da organização em atividades públicas, nos Poderes Executivo, Legislativo, Ministério Público e Judiciário e corrupção de agentes públicos;

e) A tendência de durabilidade;

f) A conexão com outras organizações, no mesmo ramo ou em ramo diferente, quando não a atividade em vários ramos;

g) A coação, mediante violência, chantagem ou aproveitamento da condição de pessoas não participantes, mas que passam a ser auxiliares ou coniventes e que vivem sob a imposição de grave dano em caso de delação;

b) Mais de três pessoas.

Conforme Fausto de Sanctis, não é possível, entretanto, uma conceituação formalmente rígida de crime organizado, uma vez que abrange uma série de grupos criminosos distintos com diferentes níveis de organização e expansão (DE SANCTIS, op. cit., cap. 1).

Entretanto, seja qual for o conceito adotado, com a edição da Lei $\mathrm{n}^{\circ}$ 12.850/2013 já podemos identificar alguns requisitos legais para configuração de uma organização criminosa, quais sejam: associação de quatro ou mais pessoas; estrutura ordenada, caracterizada pela divisão de tarefas; que visa o lucro mediante a prática de crimes; tais crimes devem ser punidos com penas máximas superiores quatro ou que eles tenham caráter transnacional, independentemente da quantidade da pena. 
Investigação de desvio de recursos públicos na Polícia Federal

\section{I DA HIERARQUIA PADRÃO ÀS REDES CRIMINOSAS DIFUSAS}

Guilherme Cunha Werner, analisando as tipologias de organizações criminosas transnacionais (conforme estudo realizado pelo Escritório de Drogas e Criminalidade da Organização das Nações Unidas), verificou uma mudança de paradigma de organização, de um modelo baseado em uma rígida estrutura hierarquizada, como no caso das máfias italianas, às redes criminosas difusas atuais, ideia aplicável, por exemplo, aos grupos terroristas internacionais que atuam em células (WERNER, op. cit., p. 92).

Se anteriormente era possível perceber que os grupos criminosos organizados apresentavam, em geral, uma estrutura hierarquizada, com um líder bem definido, que mantém o controle da organização através de um sistema rígido de disciplina, e cuja união dos membros se baseia em fortes vínculos sociais ou de identidade étnica, atualmente se verifica a existência de organizações criminosas estruturadas em redes, fundamentadas na existência de vínculos bastante voláteis entre seus integrantes, que não estão obrigados a participar do grupo, sendo necessário apenas possuírem habilidades específicas próprias indispensáveis à consecução dos objetivos ilícitos.

Essa forma de organização objetiva justamente dificultar ou até mesmo inviabilizar a identificação do grupo e de seus membros, uma vez que, quando um de seus componentes é identificado pelas agências estatais de repressão, a rede se desfaz e se reorganiza em torno de outro líder ou líderes (ibidem, p. 97).

Assim, a estruturação em rede confere "aos líderes e às associações criminosas um nível de cooperação e distanciamento, diminuindo a sua vulnerabilidade frente a ações dos órgãos responsáveis pela manutenção da lei e da ordem" (ibidem, p. 101).

O modelo de estruturação em redes difusas é perfeitamente aplicável às organizações criminosas especializadas no desvio de recursos federais repassados às prefeituras municipais, não sendo possível identificar com clareza um líder, mas uma série de indivíduos e grupos atuando de forma concertada para a consecução de seus objetivos ilícitos, cada um executando sua função dentro da engrenagem delituosa (fornecer documentos falsos, criar empresas de fachada, forjar licitaçóes, "lavar" os recursos obtidos ilicitamente etc.), mediante uma divisão de tarefas muito bem caracterizada. 
Essa noção é importante para perceber que, nos casos de organizaçôes criminosas especializadas em desviar recursos públicos (às quais se pode aplicar o modelo de estruturação em rede), quando a investigação inicia-se a partir de notícia-crime relacionadas a fatos isoladamente considerados, sem foco na repressão à criminalidade organizada, ela tende a ter uma baixa efetividade, na medida em que pode permitir a reorganização do grupo criminoso por trás daquela prática delituosa, criando, por exemplo, novas empresas de fachada, estabelecendo novos vínculos e adotando outros modi operandi, dificultando a desarticulação de todo o grupo e possibilitando que alguns dos envolvidos saiam impunes.

\section{Proposta de Tratamento das Notícias-Crime de Desvio de Recursos públicos repassados às Prefeituras Municipais}

Do que foi exposto até aqui e em consonância com o que estabelece dispõe o Art. $3^{\circ}$, $\$ 2^{\circ}$, e Art. $9^{\circ}$, ambos da Instrução Normativa no. 108-DG/PF, a qual disciplinou a possibilidade de implantação de rotinas prévias à instauração de inquéritos policiais no âmbito da Polícia Federal, que visem ao tratamento de informações, à classificação e ao agrupamento das notícias de crime, de acordo com as circunstâncias do cometimento da prática delituosa ou de sua autoria, a fim de otimizar os recursos empregados nas investigações, propõe-se uma metodologia de tratamento prévio das notícia-crime de desvio de recursos públicos federais repassados às prefeituras, nos moldes acima elencados.

Esse tratamento prévio objetiva não só verificar a existência de investigações já em andamento, como também, por exemplo: (i) identificar a atuação organizações criminosas especializadas e seus possíveis integrantes; (ii) descortinar a forma de atuação do grupo criminoso; (iii) levantar o patrimônio dos envolvidos e compatibilidade do modo de vida com as possíveis fontes de renda declaradas; (iv) verificar o possível envolvimento de servidores públicos e agentes políticos, especialmente aqueles detentores de prerrogativa de foro; e (v) delimitar a área de atuação da organização criminosa, em quais municípios ela atua, por exemplo.

Dessa forma, é possível o agrupamento de mais de uma notícia-crime em apenas um procedimento investigativo, quando se verificar a conexão entre os fatos noticiados, ainda que tenham ocorrido em municípios 
distintos, mas que possivelmente possam ser atribuídos a uma determinada organização especializada no desvio de recursos públicos. Assim, ao invés de objetivar apenas e tão somente a resolução de uma dada infração penal, as investigações devem passar a ter um objetivo mais amplo, que ó combate à criminalidade organizada.

Como já falamos, as organizações criminosas especializadas no desvio de recursos públicos federais destinados às prefeituras atuam em forma de redes difusas, o que dificulta a sua identificação e desarticulação, principalmente quando não se possui uma visão global de toda a engrenagem delituosa por trás dos desvios.

A análise preliminar das notícias-crime de desvio de recursos públicos federais repassados às prefeituras, com utilização de técnicas análise criminal ${ }^{2}$ e de inteligência policial, buscando agrupar aquelas em que seja possível a identificação de uma organização criminosa específica pode resultar em uma maior efetividade das investigações, do ponto de vista do combate à criminalidade organizada, sem falar na economia de recursos, tanto humanos, quanto materiais, com a redução do passivo de inquéritos em andamento ou por instaurar.

Pois, conforme Rodrigo Carneiro Gomes, a inteligência aplicada às atividades de polícia judiciária e investigação criminal pode contribuir decisivamente com o enfrentamento da criminalidade organizada, provendo as polícias de informações estratégicas que possibilitem a identificação de grupos criminosos, do modus operandi e da divisão de tarefas, individualização de seus integrantes e comandos hierárquicos e identificação da área geográfica de atuação, dentre outras (GOMES, 2010, p. 111).

Assim, identificando-se a atuação de uma determinada organização criminosa especializada no desvio de recursos públicos federais repassados aos municípios, em mais de uma notícia-crime, podem elas ser reunidas em um só procedimento investigatório, o que facilitará a desarticulação de toda engrenagem delituosa e o indiciamento de todos os envolvidos, possibilitan-

2 Conforme Luís Fiães Fernandes, "podemos definir a análise criminal como o conjunto de actividades que, pela aplicação de metodologias (...) e técnicas analíticas (...) a dados e informações de natureza policial (...), tem como objectivo produzir" conhecimentos relevantes para as esferas de decisão. "Esta inteligência temo como objectivos identificar os riscos de natureza criminal emergente e antecipar a actividade criminosa, ou seja, apoiar as decisões estratégicas e operacionais, aos vários níveis hierárquicos e funcionais, contribuindo para a realização dos fins da prevenção, investigação criminal e combate à criminalidade" (FERNANDES, 2012, p. 140). 
do também um melhor aproveitamento das técnicas de investigação previstas na legislação vigente, especificamente na Lei no 12.850/2013.

Além disso, a metodologia proposta pode resultar em uma maior economia de recursos humanos e materiais, com a redução do número de inquéritos policiais em andamento, contribuindo para uma maior eficiência e efetividade das investigações.

\section{Da Operação Geleira}

O Estado do Piauí, com capital em Teresina, encontra-se situado no nordeste brasileiro, em uma das regióes menos desenvolvidas e mais pobres do país. Possui uma população total estimada de 3.212.180 de habitantes, conforme dados do Instituto Brasileiro de Geografia e Estatística (IBGE) e 224 municípios.

Possui uma das populações mais carentes do país, sendo uma de suas características a grande desigualdade social gerada por anos e anos de descaso do poder público para com as necessidades regionais, especialmente o problema da seca.

Para compensar essa grave situação econômica, os municípios do Piauí recebem elevadas somas de recursos públicos, principalmente através de transferências constitucionais, legais e voluntárias da União, para aplicação em políticas públicas de promoção da saúde, educação, emprego e de combate à seca, principalmente.

Os recursos são repassados diretamente às prefeituras municipais, que ficam encarregadas de sua regular aplicação. Contudo, a aplicação desses recursos se dá muitas vezes sem qualquer fiscalização e acompanhamento por parte dos órgãos de controle competentes, o que favorece a ocorrência de desvios, agravando ainda mais a situação da região.

Essa é uma prática comum em todo o país, mas possui maior frequência nos estados do Nordeste, em razão das peculiaridades regionais já apontadas anteriormente.

Tal situação cria terreno fértil para o nascimento e desenvolvimento de verdadeiras estruturas criminosas dentro e ao redor das prefeituras, que 
Investigação de desvio de recursos públicos na Polícia Federal

se alimentam das deficiências das instâncias de controle internas e externas, fazendo com que bilhões de reais se percam todos os anos com o desvio de recursos públicos e a corrupção.

São criadas empresas de fachada, cujos responsáveis especializam-se em fornecer documentos inidôneos para justificar gastos públicos (notas fiscais "frias", por exemplo), assim como empresas de consultoria (escritórios de contabilidade e jurídicos), os quais, por sua vez, prestam uma espécie de "assessoria" às prefeituras indicando formas ludibriar os órgãos de fiscalização, servindo inclusive de elo de ligação com os falsos empresários.

Foi assim que, em 2009, a partir de informe recebidos pelo Núcleo de Inteligência Policial da Superintendência de Polícia Federal no Piauí dando conta da existência de um grupo de pessoas que estariam criando empresas de fachada, com a finalidade de fornecer documentos falsos a diversas prefeituras piauienses.

A investigação dos fatos noticiados foi formalizada através do Inquérito Policial $n^{\circ} 37 / 2009-S R / P F / P I$, ainda sob a vigência da Lei ${ }^{\circ}$ 9.034/1995, que dispunha sobre a utilização de meios operacionais para a prevenção e repressão de ações praticadas por organizações criminosas, revogada pela Lei $\mathrm{n}^{\circ} 12.850 / 2013$.

Durante a investigação, verificou-se a atuação de uma verdadeira organização criminosa que atuava em diversos municípios piauienses, desviando recursos públicos federais destinados às prefeituras. Tal organização não apresentava uma hierarquia padrão, mas um elevado grau de organização e divisão de tarefas, assemelhando-se ao modelo de rede criminosa difusa mencionado anteriormente.

O grupo criminoso organizado em questão era integrado pelos prefeitos dos municípios envolvidos, falsos empresários, falsários, empresas de fachada e uma empresa de contabilidade que era responsável pela montagem dos processos licitatórios fraudulentos e pelas prestações de contas fictícias, utilizadas para justificar as despesas com recursos públicos federais, dentre outros, que realizavam cada um o seu papel dentro da estrutura delituosa.

Uma característica dessa investigação é que ela não partiu de um determinado fato ocorrido em uma dada prefeitura, mas de um trabalho de inteligência, que identificou um grupo de falsos empresários que fornecia 
documentos falsos a diversas prefeituras, muita das vezes com a intermediação de um determinado escritório de contabilidade. Dessa forma, foi possível identificar toda a engrenagem delituosa e fazer uso das ferramentas de investigação e repressão ao crime organizado que a legislação à época disponibilizava, o que reforça a tese da necessidade de tratamento prévio das notíciascrime que versem sobre desvio de recursos públicos federais em prefeituras, com foco na repressão à criminalidade organizada, garantindo-se uma maior efetividade dos inquéritos policiais.

Foi assim que, em 19 de janeiro de 2011, foi deflagrada a Operação Geleira pela Superintendência de Polícia Federal no Piauí, em ação conjunta com a Controladoria Geral da União (CGU) e com o Ministério Público Federal (MPF), com a participação de 325 (trezentos e vinte e cinco) policiais federais de vários estados e 28 (vinte e oito) servidores da CGU, sendo cumpridos a 84 (oitenta e quatro) Mandados de Busca e Apreensão e 30 (trinta) Mandados de Prisão com a finalidade de desarticular uma rede criminosa especializada na comercialização de notas fiscais frias e desvio de recursos públicos de prefeituras do interior do Estado do Piauí. Entre os presos, vários prefeitos e ex-prefeitos dos municípios investigados.

O rol de crimes investigados foi extenso: desvio de recursos públicos pelos gestores municipais envolvidos, formação de quadrilha, falsificação de documentos públicos e privados, falsidade ideológica, uso de documento falso, inserção de dados falsos em sistema de informática, tráfico de influência, corrupção, crimes previstos na Lei de Licitações, sonegação de tributos e lavagem de dinheiro.

\section{Conclusão}

Como visto, vigora no Brasil o sistema de investigação preliminar criminal policial, que é formalizada mediante inquérito policial, procedimento pré-processual de natureza administrativa, conduzido pelas polícias judiciárias (Federal e polícias civis estaduais) e presidio por delegado de polícia. O inquérito policial possui dupla função de apurar supostas infrações criminais, colhendo indícios da materialidade e autoria, assim como evitar acusações infundadas.

Na Polícia Federal, as atividades de polícia judiciária encontram-se regulamentadas atualmente pela Instrução Normativa n ${ }^{\circ} 108-\mathrm{DG} / \mathrm{PF}$, de 08 
de novembro de 2016, a qual disciplinou a possibilidade de análise prévia das notícia-crime, devendo ser observada a existência de investigação conexa em andamento, projetos ou rotinas de trabalho formalmente instituídas que visem ao tratamento de informações, à classificação e ao agrupamento das notícias de acordo com as circunstâncias do cometimento da prática delituosa ou de sua autoria, a fim de otimizar os recursos empregados nas investigações.

Embora o princípio da obrigatoriedade também se aplique à fase prévia da ação penal, determinando ao delegado de Polícia Federal seja instaurado o competente inquérito policial assim que tomar conhecimento de uma infração penal, deve a autoridade de polícia judiciária da União, de acordo com critérios de conveniência e oportunidade, realizar a análise preliminar das notícias-crime, dando prioridade às investigações mais relevantes.

Não se trata da adoção pura e simples do princípio da oportunidade em relação aos inquéritos policiais, mas de uma obrigatoriedade mitigada ou diferida, em que o delegado de Polícia Federal, de acordo com critérios objetivos, definidos pelo comando da instituição, como gravidade da lesão, relevância do bem jurídico tutelado e possível envolvimento de organizações criminosas, pode, a partir da análise e classificação prévia das notícia-crime, eleger aquelas que são prioritárias, agrupando-as, sempre que possível e visando a repressão do crime organizado, em um só procedimento investigativo.

Dessa forma, além de priorizar a investigação de fatos juridicamente relevantes, há um melhor aproveitamento dos recursos humanos e materiais disponíveis.

Nesse contexto, a investigação de desvios de recursos públicos federais repassados às prefeituras municipais assume grande importância para a instituição, uma vez que o combate à corrupção e ao crime organizado foi eleito como prioridade da Polícia Federal.

Em razão da complexidade dos fatos e das características das organizações criminosas especializadas no desvio de recursos públicos federais repassados às prefeituras (estruturadas em redes difusas), a investigação dessa modalidade delituosa não pode mais ser realizada a partir da instauração de inquéritos policiais para apurar fatos isoladamente considerados.

Verifica-se a necessidade da adoção de rotinas de tratamento e análise prévia das notícias-crime, classificando e reunindo aquelas que apresentem 
indícios da atuação de uma determinada organização criminosa, permitindose o agrupamento delas em um único procedimento investigatório, com foco no desbaratamento de toda engrenagem criminosa por trás dos fatos investigados, evitando-se, assim, a instauração de inúmeros inquéritos para apurar fatos isolados e fora do contexto de repressão da criminalidade organizada.

Alex Silva Chagas

Delegado de Polícia Federal. Bacharel em Direito pela Faculdade de Direito da Universidade Federal da Bahia. Mestrando em Ciências Policiais pelo Instituto Superior de Ciências Policiais e Segurança Interna da Polícia de Segurança Pública de Portugal. Chefiou a Delegacia de Repressão a Crimes Financeiros e Corrupção da Superintendência de Polícia Federal no Piauí

E-MAIL:ALEX.ASC@DPF.GOV.BR

\section{Investigation OF Public Funds \\ Misappropriation at the Federal Police: \\ PRELIMINARY ANALYSIS AND CLASSIFICATION OF CRIMINAL NOTICES}

\section{ABSTRACT}

This scientific paper intend to examine how the brazilian Federal Police receive, treat and distribute criminal notices of federal public funds misappropriation passed on to city halls. How the immediately instauration of numerous police inquiries, from separately considered criminal notices, without any previous treatment, causes the low effectiveness of the investigations in those cases, in the moment it loses focus in the possible performance of organized crime groups, not to mention the inadequate use of the few available human and material resources. It is proposed that, in spite of the obligation to initiate the police inquiry, the criminal notices of federal public funds misappropriation destined to city halls be preliminarily analyzed, with the objective of identifying the possible action of a criminal organization in common, And later assembled in a single investigative procedure, facilitating the disarticulation of the entire criminal group and the punishment of all those involved.

Keywords: Police Inquiry. Principle of Mandatory Prosecution. Criminal Notice. Public Funds Misappropriation. Organized Crime. Preliminary Analysis. 


\title{
Investigación de Desvio de Recursos Públicos en la Policía Federal: análisis preliminar y CLASIFICACIÓN DE LAS NOTICIAS DE CRIMEN
}

\author{
RESUMEN
}

El presente artículo científico tiene la pretensión de analizar la forma con que normalmente son recibidas, tratadas y distribuidas, en la Policía Federal, las noticias de crimen de desvío de recursos públicos federales repasados a las alcaldías municipales. En estos casos, la instauración de numerosas investigaciones policiales, de inmediato, a partir de noticias de crímenes consideradas aisladamente, sin ningún tratamiento previo, contribuye a la baja efectividad de las investigaciones, a partir del momento en que se pierde el foco en la posible actuación de una organización delictiva, sin hablar del uso inadecuado de los pocos recursos humanos y materiales disponibles. Se propone que, a pesar de la obligatoriedad de la instauración de la investigación policial, las noticias de crimen que versen sobre el desvio de recursos públicos federales destinados a las alcaldías sean preliminarmente analizadas, con el objetivo de identificar la posible actuación de una organización criminal en común, Y posteriormente reunirlas en un solo procedimiento investigativo, facilitando la desarticulación de todo el grupo criminal y la punición de todos los involucrados.

Palabras clave: Investigación Policial. Obligatoriedad. Noticias de Crimen. Desvío de recursos públicos. Crimen organizado. Análisis Preliminares.

\section{REFERÊNCIAS}

BARBOSA, Adriano Mendes. Ciclo do Esforço Investigativo Criminal. Revista Brasileira de Ciências Policiais, v. 1, n. 1, p. 153-179, 2010. Disponível em: https://periodicos.pf.gov.br/index.php/ RBCP/article/viewFile/32/10. Acesso em: 21/11/2016.

CORREA, Vanessa Pitrez Aguiar. O papel da polícia judiciária no Estado Democrático de Direito. Segurança Pública \& Cidadania, v. 2, n. 1, p. 39-54, 2009. Disponível em: https://periodicos.pf.gov.br/ index.php/RSPC/article/viewFile/82/84. Acesso em: 21/11/2016.

DE SANCTIS, Fausto Martin. Crime Organizado e Lavagem de Dinheiro: destinação de bens apreendidos, delação premiada e responsabilidade social. São Paulo: Saraiva, 2015. E-Book.

GOMES, Rodrigo Carneiro. Prevenir o crime organizado: inteligência policial, democracia e difusão do conhecimento. Segurança Pública \& Cidadania, v. 2, n. 2, p. 107-137, 2010. 
HAYASHI, Felipe Eduardo Hideo. Corrupção: combate transnacional, compliance e investigação criminal. Rio de Janeiro: Lumen Juris, 2015.

LEMOS JÚNIOR, Arthur Pinto de. A investigação criminal diante das organizações criminosas e o posicionamento do Ministério Público. Revista dos Tribunais, v. 91, p. 411-449. Disponível em: http:// www2.tjce.jus.br:8080/esmec/wp- content/uploads/2010/11/ crimes_organizados.pdf. Acesso em: 22/11/2016.

LOPES JR. Aury. Direito Processual Penal. São Paulo: Saraiva, 2016. E-Book.

LOPES JR., Aury. Sistemas de Investigação Preliminar no Processo Penal. Rio de Janeiro: Lumen Juris, 2006.

LOPES JUNIOR, Edmílson. As redes sociais do crime organizado: a perspectiva da nova sociologia econômica. Revista Brasileira de Ciências Sociais, São Paulo, v. 24, n. 69, p. 53-68, 2009.

Disponível em: http://www.scielo.br/scielo.php?script=sci_arttext \&pid=S010269092009000100004\&lng=en\&nrm=iso. Acesso em: $21 / 11 / 2016$

MARCÃO, Renato. Curso de Processo Penal. São Paulo: Saraiva, 2014. E-Book.

MORO, Sergio Fernando. Crime de Lavagem de Dinheiro. São Paulo: Saraiva, 2010. E-Book. NUCCI, Guilherme de Souza. Manual de Processo Penal e Execução Penal. Rio de Janeiro:Forense, 2016. E-Book.

PEREIRA, Eliomar da Silva. Teoria da Investigação Criminal: uma introdução jurídico- científica. São Paulo: Almedina, 2010.

SAAD-DINIZ, Eduardo; CASAS, Fabio; COSTA, Rodrigo de Souza (org.). Modernas Técnicas de Investigação e Justiça Penal Colaborativa. São Paulo: LiberArs, 2015.

SILVA, Márcio Alberto Gomes. Inquérito Policial: Uma Análise Jurídica E Prática Da Fase Pré-Processual. Campinas: Millennium, 2016.

VALENTE, Manuel Monteiro Guedes. A Investigação do Crime Organizado: buscas domiciliárias nocturnas, o agente infiltrado e intervenção nas comunicações. Em: Criminalidade Organizada e 
Investigação de desvio de recursos públicos na Polícia Federal

Criminalidade de Massa. Almedina, 2009, pp. 159-184.

VALENTE, Manuel Monteiro Guedes. Teoria Geral do Direito Policial.

Coimbra: Almedina, 2016.

WERNER, Guilherme Cunha. O crime organizado transnacional e as redes criminosas: presença e influência nas relaçóes internacionais contemporâneas. Universidade de São

Paulo. Disponível em http://www.teses.usp.br/teses/ disponiveis/8/8131/tde-04092009163835/. Acesso em: $21 / 06 / 2016$

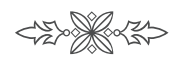

